\title{
IL-27 Mediates Neutrophils Infiltration at the Maternal and Fetal Interface in Preterm Labor With Infection
}

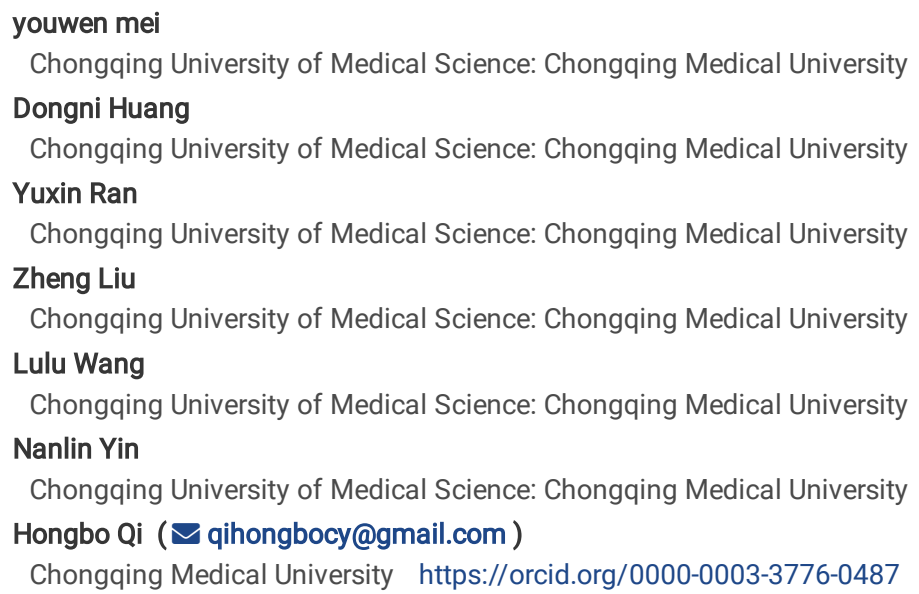




\section{Abstract \\ Objective}

To reveal the role of IL-27 in neutrophils infiltration at the maternal and fetal interface in preterm labor with infection (PTLI).

\section{Methods}

The expression of IL-27 receptor and the number of neutrophils (MPO + cells) at the maternal and fetal interface of pregnant women were compared between PTLI group and term labor (TL) group. Using LPS-induced preterm labor IL-27Ra-/- mice, the role of IL-27 in neutrophils infiltration at the maternal and fetal interface was investigated.

\section{Results}

The expression of IL-27Ra and neutrophils number at the maternal and fetal interface in the PTLI group were higher than those in the TL group in pregnant women. Compared with PBS-treated mice, LPS-treated mice had increased infiltrating neutrophils at the maternal and fetal interface. Meanwhile, LPS-induced IL-27Ra-/- mice had less neutrophil infiltration than LPS-induced WT mice.

\section{Conclusion}

IL-27 promotes neutrophil infiltration at the maternal and fetal interface in PTLI.

\section{Highlights}

1, IL-27 signaling and neutrophils infiltration increased at the maternal and infant interface in preterm labor with infection

2, IL-27 could promote neutrophils infiltration at the maternal and fetal interface

3, Neutrophils counts in peripheral blood were higher in pregnant women from PTLI group than TL group, positively related with that at the maternal and fetal interface

\section{Introduction}

Infection is associated with about $40 \%$ preterm labor (PTL), which accounts for $75 \%$ perinatal mortality and over $50 \%$ long-term morbidity $[1,2]$. In preterm labor with infection (PTLI), inflammation is present throughout all gestational tissues[3]. Infiltrative leukocytes are the main resource of proinflammatory factors, of which neutrophils rank the first. In preterm labor, neutrophil abundance at the maternal and fetal interface had increased 5 to 53 fold[4-6] with increased survival[5]. Their gene expression profile changed from homeostatic to a proinflammatory phenotype[6], producing myeloperoxidase (MP0) or neutrophil extracellular traps et al[7]. A previous human study clearly demonstrated that intrauterine inflammation increased the risk for PTL[8], thus neutrophils at the maternal and fetal interface was speculated to increase the risk of PTL.

Interleukin-27 (IL-27), a member of IL-6/IL-12 family, is secreted mainly by antigen-presenting cells[9]. IL-27 receptor (IL-27R) is a heterodimer composed of IL27Ralpha (IL-27Ra) and glycoprotein 130 subunits. IL-27Ra is unique to IL-27R, while gp130 is also a subunit of IL-6 receptor and IL-35 receptor. IL-27 could significantly enhance TNF-a and IL-6 secretion from THP-1 cells, promoting sepsis progression [10]. IL-27 was also a novel candidate diagnostic biomarker for bacterial infection in critically ill children. At a cut-point value of $\geq 5 \mathrm{ng} / \mathrm{ml}$, serum IL-27 had a specificity and a positive predictive value of $>90 \%$ in predicting infection, better than procalcitonin[11]. In caecal ligation puncture-induced lung inflammation mice model, elevated IL-27 levels were observed in the lung, serum, and bronchoalveolar lavage fluids, and IL-27 neutralizing antibody could reduce lung injury and improve survival[12, 13]. Our previous team work also demonstrated that IL-27 could induce a proinflammatory response in human fetal membrane, mediating in preterm labor[14]. In regards of the above evidence, we hypothesized that IL-27 could participate in PTLI by regulating neutrophils infiltration at the maternal and fetal interface.

\section{Materials And Methods}

\section{Human samples}

Pregnant women who had suffered PTLI from September,2018 to September,2020 in the First Affiliated Hospital of Chongqing Medical University were enrolled as study group-PTLI group, while those who had term labor at the parallel period were randomly selected as control group-TL group. Preterm labor and term labor were defined according to the guidelines of the American College of Obstetricians and Gynecologists. The criteria of infection was based on the following items: temperature $>37.6$ centigrade, white cell count $>15^{\star} 10^{\wedge} 9 / \mathrm{L}$, C-reactive protein $>10 \mathrm{mg} / \mathrm{L}$, or histological signs of chorioamnionitis[15]. Those patients with pregnancy complications such as pregnancy hypertension, intrahepatic cholestasis of pregnancy, placenta abruption and chronic diseases were excluded. Human FMs were collected within 30 minutes after delivery. These samples were stored as required for westen blot, real-time quantitative PCR (qPCR) and immunohistochemistry (IHC). The patients' informed consent was obtained, and ethics approval was gained from the Ethics Committee of the First Affiliated Hospital of Chongqing Medical University (2019-137). 


\section{Mouse Models}

IL-27Ra knock out (IL-27Ra-/-) mice on C57BL/6 background were purchased from Jackson Laboratory in the USA, and C57BL/6 mice purchased from experimental animal center of Chongqing medical university were designated as wild type (WT) mice. The absence of IL-27Ra gene was confirmed by gene identification test with mice's tail. All mice were housed under specific pathogen free conditions during the whole course of the study. Two female mice (8-12 weeks) were mated with one male of the same genotype at dawn. The vaginal plugs were checked the next morning, whose presence indicated gestational day of 0.5 . The mice model of PTLI was established as previously reported[16, 17]. Briefly, at gestational day of 16.5 , the pregnant mice were intraperitoneally

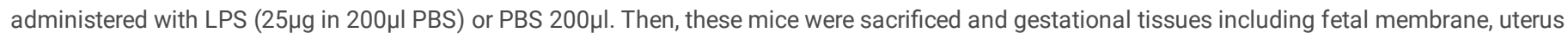
myometrium, and decidua were harvested 6 hours after LPS/PBS injection. All human and animal experiments were approved by the Clinical Research Ethics Committee of the First Affiliated Hospital of Chongqing Medical University (2019-137).

\section{Extraction of total RNA and qPCR}

Total RNA was extracted by RNAiso Plus (Takara Bio Inc., Tokyo, Japan), followed by reverse transcription using a PrimeScript RT Reagent Kit (Takara Bio Inc., Tokyo, Japan). Thereafter, generated cDNA from 1 ug RNA was subjected to real-time PCR analysis with SYBR Premix Ex Taq II kit (MCE, Shanghai, China), using thermal cycler dice real time system. Relative quantity of target gene expression to $\beta$-actin gene were calculated with comparative threshold cycle (CT) method, and primers for each target gene were presented in Sup Table 1.

\section{Western Blot}

Total protein was harvested from human FMs by RIPA lysis buffer (ZSGB-BIO, Beijing, China) containing PMSF (ZSGB-BIO, Beijing, China). Equal amount of protein $(40 \mu \mathrm{g})$ was electrophoresed on 10\% SDS-polyacrylamide gels (Invitrogen) and blotted onto PVDF membranes. The membranes were incubated overnight with IL-27Ra (1:1000, Affinity, Jiangsu, China) antibody after blocked in 5\% nonfat milk for 2 hours. Then, the PVDF membranes were incubated with an HRP-conjugated anti-IgG secondary antibody, followed by band detection with an ECL chemiluminescent detection system. The blots were imaged and quantified using ImageJ software, and the results were reported as IL-27Ra/ $\beta$-actin ratio.

\section{Hematoxylin and eosin (H\& E) staining and immunohistochemistry (IHC)}

For $\mathrm{H} \& \mathrm{E}$ staining, paraffin sections were stained with hematoxylin and eosin. For IHC, following dewaxing and rehydration, microwave antigen retrieval on paraffin sections was performed. Nonspecific staining was blocked with $3 \% \mathrm{H} 2 \mathrm{O} 2$, followed by nonimmune block with $10 \%$ normal goat serum. Then, tissue sections were incubated with primary antibodies overnight at 4 centigrade (IL-27Ra 1囚200,Santa Crue, China; MPO 1:300, protein-tech, China; Ly6g:1:200, protein-tech, China). After thorough washes, the sections were incubated with biotinylated goat anti-mouse/Rabbit IgG. Positive antibody binding was detected with diaminobenzidine, followed by hematoxylin staining. The cells positive for each biomarker in gestational tissues were enumerated on three fields at $x 400$ magnifications. All measurements were carried out by two independent researchers without knowing the experimental protocols in advance.

\section{Statistical Analysis}

Statistical analysis was performed by Prism software. Student's t test or Mann-Whitney U test were used to assess continuous variables according to its distribution. Chi-square test was used to assess categorical variables. P value 0.05 was considered statistically significant.

\section{Results}

\section{Expression of IL-27/IL-27Ra at the maternal and fetal interface from PTLI and TL groups}

Our previous team work had proved that serum IL-27 level was higher in the PTL group than women in the TL group[14]. In the present study, qPCR analyses showed increased IL-27 and IL-27Ra mRNA expression in human FMs from PTLI group compared to TL group (Fig. 1A and Fig. 1B). Western blot analysis confirmed that the expression of IL-27Ra in FMs was significantly higher in the PTLI group (Fig. 1C and 1D). Our H\& E staining had showed the structure of human FMs, which consisted of epithelial cells, interstitial fibrous layer, chorion layer and decidua parietalis layer (Fig. 1E). In the immunostaining tissue sections, IL-27Ra was expressed in amnion cells, chorion cells and decidua cells. It could be observed that the number of IL-27Ra positive cells and color intensity were enhanced in PTLI group (Fig. 1G) than TL group (Fig. 1F).

\section{Neutrophils infiltration at the maternal and fetal interface of human}

Neutrophils' marker MPO was analyzed by qPCR in human FMs. As a result, MPO mRNA expression was higher in PTLI group than that in TL group (Fig. 2A). In the immunostaining tissue sections, neutrophils (MPO + cells) could be seen in interstitial fibrous layer, chorion layer and decidua parietalis layer. The major location of initial neutrophil infiltration is choriodecidual junction (Fig. 2B and Fig. 2C). In parallel with qPCR analyses, the number of MPO + cells / high performance fortran(HPF)was higher in PTLI group than that in TL group (Fig. 2D).

\section{Neutrophils infiltration at the maternal and fetal interface of mice}

Then, we explored neutrophils infiltration in myometrium and decidua in pregnant WT and IL-27Ra -/- mice. qPCR analyses demonstrated that Ly6g mRNA expression was enhanced in myometrium and decidua in LPS-treated mice than their corresponding PBS-treated mice. Furthermore, the enhancement was significantly attenuated in IL-27Ra-/-mice compared with that in WT mice (Fig. 3A and Fig. 3D). In Immunohistochemistry sections, neutrophils (Ly6g + cells) could be seen in myometrium and decidua, whose number/HPF was in consistent with Ly6g mRNA expression (Fig. 3B,3C and Fig. 3E,3F), suggesting that IL27 signaling could promote neutrophils infiltration in myometrium and decidua of mice model. 


\section{Neutrophils in peripheral blood in pregnant women of PL group and TL group}

As neutrophils at the maternal and fetal interface were entirely maternal origin[6], we compared the neutrophils number in peripheral blood according to the routine blood test on admission between PTLI group $(n=18)$ and TL group $(n=36)$. As a result, neutrophils number and percentage of neutrophils in the PTLI group were significantly higher than those in the TL group (Table 1).

Table 1

Characteristics of pregnant women from TL and PTLI groups

\begin{tabular}{|c|c|c|c|c|c|c|c|c|c|c|c|}
\hline Characteristic & $\begin{array}{l}\text { Matemal } \\
\text { age } \\
\text { (Mean } \pm \\
\text { SD) }\end{array}$ & $\begin{array}{l}\begin{array}{l}\text { BMI } \\
\text { before } \\
\text { pregnant }\end{array} \\
\text { (Mean } \pm \\
\text { SD) }\end{array}$ & $\begin{array}{l}\text { BMl of } \\
\text { pregnant } \\
\text { (Mean } \pm \\
\text { SD) }\end{array}$ & $\begin{array}{l}\text { Gravity } \\
\text { times(n) }\end{array}$ & $\begin{array}{l}\text { Parity } \\
\text { times(n) }\end{array}$ & $\begin{array}{l}\text { GA } \\
\text { (weeks) }\end{array}$ & $\begin{array}{l}\text { Total } \\
\text { leucocyte } \\
\text { count }\left(* 10^{\wedge} 9 / \mathrm{L} \text {, }\right. \\
\text { Mean } \pm \text { SD) }\end{array}$ & $\begin{array}{l}\text { Neutrophil } \\
\text { count } \\
\text { (Mean } \pm \\
\text { SD) }\end{array}$ & $\begin{array}{l}\text { Percentage } \\
\text { of } \\
\text { neutrophils } \\
\text { (Mean } \pm \\
\text { SD) }\end{array}$ & $\begin{array}{l}\text { lymphocyte } \\
\text { count } \\
\text { (Mean } \pm \\
\text { SD) }\end{array}$ & $\begin{array}{l}\text { Perce } \\
\text { of } \\
\text { lympl } \\
\text { (Meal } \\
\text { SD) }\end{array}$ \\
\hline $\mathrm{TL}(\mathrm{n}=36)$ & $\begin{array}{l}28.53 \pm \\
2.24\end{array}$ & $\begin{array}{l}20.17 \pm \\
1.85\end{array}$ & $\begin{array}{l}25.82 \pm \\
2.07\end{array}$ & $1(1-2)$ & $0(0-1)$ & $\begin{array}{l}33.09 \pm \\
2.37\end{array}$ & $9.52 \pm 1.86$ & $\begin{array}{l}7.43 \pm \\
2.05\end{array}$ & $\begin{array}{l}78.53 \pm \\
5.13\end{array}$ & $1.46 \pm 0.78$ & $\begin{array}{l}14.69 \\
4.15\end{array}$ \\
\hline PTLI(n= 18) & $\begin{array}{l}27.72 \pm \\
4.9\end{array}$ & $\begin{array}{l}20.96 \pm \\
1.68\end{array}$ & $\begin{array}{l}25.78 \pm \\
1.63\end{array}$ & $2(1-3)$ & $0(0-1)$ & $\begin{array}{l}39.62 \pm \\
0.8\end{array}$ & $14.55 \pm 3.31$ & $\begin{array}{l}12.25 \pm \\
3.28\end{array}$ & $\begin{array}{l}83.59 \pm \\
5.22\end{array}$ & $1.49 \pm 0.42$ & $\begin{array}{l}10.76 \\
3.85\end{array}$ \\
\hline$P$ & 0.408 & 0.137 & 0.951 & 0.101 & 0.384 & $\begin{array}{l}< \\
0.0001\end{array}$ & $<0.0001$ & $<0.0001$ & 0.002 & 0.849 & 0.001 \\
\hline
\end{tabular}

\section{Discussion}

Neutrophils infiltration at the maternal and fetal interface is a characteristic feature of PTLI[18], accompanied by abundant proinflammatory cytokines[19]. It was observed that neutrophil depletion did reduce the levels of pro-inflammatory factors such as IL-1 $\beta$ at the maternal and fetal interface[20], and neutrophils in the chorionic decidua can mediate inflammation and immune imbalance[6]. Furthermore, neutrophil recruitment at the maternal and fetal interface may contribute to tissue injury by vital neutrophil extracellular traps formation, prolonged neutrophil viability, and neutrophil degranulation, reactive oxygen species production and inflammatory chemokine/cytokine production during infection[7]. IL-27 is a member of IL-6/IL-12 family. Previous studies reported that functional inhibition of IL-6 led to reduced systemic and pulmonary neutrophilia[21], and anti-IL-6 receptor monoclonal antibody abrogated neutrophil recruitment[22]. In mice model of streptococcus pneumoniae infection, IL-12 can promote pulmonary neutrophil recruitment[23]. Therefore, it may be rational to speculate that IL-27 may also promote neutrophil infiltration under certain context. Indeed, IL-27R signaling contributed to Ly6G + neutrophils accumulation in diseased aorta of mice model with aortic aneurysm[24]. Our previous work had suggested that IL-27 can promote the inflammatory process of human FMs in preterm labor[17]. Therefore,we speculated that IL-27 could contribute to the increased inflammation by affecting neutrophils infiltration at the maternal and fetal interface.

The present study had the following three findings. Firstly, intrauterine infection induced neutrophils infiltration at the maternal and fetal interface in both human and mice models. This was in keeping with previous studies that massive influx of neutrophils was detected at decidua in mice model of LPS induced PTL[4, 6]. Secondly, it demonstrated that IL-27 was positively related with neutrophils infiltration upon LPS exposure. Thirdly, counts and percentage of neutrophils in peripheral blood were higher in the PTLI group than those in the TL group, positively related with neutrophils at the maternal and fetal interface. It suggested that neutrophils extravasated from peripheral blood quickly to the maternal and fetal interface[25].

Neutrophils infiltration is mainly regulated by chemokines[26] and adhesive factors, such as L-selectin and intercellular cell adhesion molecule-1[27]. A previous study demonstrated that IL-27 could augment CXCL8 expression in cord blood dendritic cells[28]. CXCL8 was an important chemokine for neutrophils infiltration[29] and genes encoding CXCL8 were associated with labor onset in humans[30]. IL-27 also augmented the secretion of intercellular cell adhesion molecule-1[31, 32]. The above conclusions helped to explain that in LPS-treated IL-27Ra-/- mice, neutrophil infiltration was less abundant in our study. However, some studies conversely stated that IL-27 could downregulate neutrophil infiltration in zymosan-induced peritonitis[33] and in mice model with C. parapsilosis infection[34]. This discrepancy may be a presentation of the dual role of IL-27 in different context, affected by multiple factors such as disease phase, animal models and interventional methods[35].

Since the mother-fetal interface is intricate and affected by many factors. Based on this, our study firstly explores the relationship between IL-27 and neutrophils in preterm birth, which helps to further clarify the dual mechanism of IL-27 and lay the foundation for further research. To the best of our knowledge, the present study was one of the first to study IL-27's role on neutrophils infiltration at the maternal and fetal interface. Furthermore, neutrophils at the maternal and fetal interface and in peripheral blood were linked up and studied. There was also certain limitation in our manuscript, such as the sampling time point was relatively simple, thus these results should be cautious to interpret.

\section{Conclusion}

In all, IL-27 promote neutrophils infiltration at the maternal and fetal interface in PTLI. Considering the critical role of inflammation in the pathogenesis of preterm birth which may contributed by neutrophils, therefore, IL-27 and neutrophils might be important intervention targets in the pathogenesis of PTLI.

\section{Abbreviations}

PTL: preterm labor, PTLI: preterm labor with infection, MPO: myeloperoxidase, IL-27:Interleukin-27, IL-27Ra:a subunit of IL-27 receptor, gp130:glycoprotein 130, TL: term labor, FMs: fetal membranes, qPCR: real-time quantitative PCR, IHC囚immunohistochemistry, IL-27Ra-/-邓IL-27Ra knock out, WT囚wild type,CT: cycle 
threshold, H\& E: Hematoxylin and eosin, HPF: high performance fortran

\section{Declarations}

\section{Ethics approval and consent to participate}

Ethics approval was gained from the Ethics Committee of the First Affiliated Hospital of Chongqing Medical University (2019-137), and Written informed consent for participation was obtained from all participants.

\section{Consent for publication}

Written informed consent for participation was obtained from the participants.

\section{Availability of data and materials}

Data and materials would be provided if requested

\section{Competing interests}

There were no competing interests to declare

\section{Funding}

This work was supported by research funding from National Natural Science Foundation of China for Youth [81801483] and the National Key R\&D Program of China [No.2016YFC1000407]

\section{Author contributions}

Youwen Mei designed the study, performed the experiments, analyzed the data, and wrote the manuscript. Nanlin Yin and Hongbo Qi designed the study, reviewed the manuscript, and supervised the project. Dongni Huang, Yuxin Ran, Zheng Liu, and Yunqian Zhou performed the experiments, and analyzed the data. All authors approved the submitted version of the manuscript.

\section{Acknowledgements}

Not Applicable

\section{References}

1. Goldenberg, R. L., J. F. Culhane, J. D. lams, and R. Romero. 2008. Epidemiology and causes of preterm birth. Lancet 371: 75-84. http://doi.org/10.1016/s0140-6736(08)60074-4.

2. DiGiulio, D. B., R. Romero, H. P. Amogan, J. P. Kusanovic, E. M. Bik, F. Gotsch, C. J. Kim, O. Erez, S. Edwin, and D. A. Relman. 2008. Microbial prevalence, diversity and abundance in amniotic fluid during preterm labor: a molecular and culture-based investigation. PloS one 3 , e3056.http://doi.org/10.1371/journal.pone.0003056.

3. Bonney, E. A., and M. R. Johnson. 2019. The role of maternal T cell and macrophage activation in preterm birth: Cause or consequence? Placenta 79, 5361.http://doi.org/10.1016/j.placenta.2019.03.003

4. Shynlova, O., T. Nedd-Roderique, Y. Li, A. Dorogin, T. Nguyen, and S. J. Lye. 2013. Infiltration of myeloid cells into decidua is a critical early event in the labour cascade and post-partum uterine remodelling. Journal of cellular and molecular medicine 17: 311 -311 24. http://doi.org/10.1111/jcmm.12012

5. Presicce, P., C. W. Park, P. Senthamaraikannan, S. Bhattacharyya, C. Jackson, F. Kong, C. M. Rueda, E. DeFranco, L. A. Miller, D. A. Hildeman, N. Salomonis, C. A. Chougnet, A. H. Jobe, and S. G. Kallapur. 2018. IL-1 signaling mediates intrauterine inflammation and chorio-decidua neutrophil recruitment and activation. JCl Insight 3.http://doi.org/10.1172/jci.insight.98306.

6. Presicce, P., M. Cappelletti, P. Senthamaraikannan, F. Ma, M. Morselli, C. M. Jackson, S. Mukherjee, L. A. Miller, M. Pellegrini, A. H. Jobe, C. A. Chougnet, and S. G. Kallapur. 2020. TNF-Signaling Modulates Neutrophil-Mediated Immunity at the Feto-Maternal Interface During LPS-Induced Intrauterine Inflammation. Frontiers in immunology 11, 558.http://doi.org/10.3389/fimmu.2020.00558.

7. Tong, M., J. A. Potter, G. Mor, and V. M. Abrahams. 2019. Lipopolysaccharide-Stimulated Human Fetal Membranes Induce Neutrophil Activation and Release of Vital Neutrophil Extracellular Traps. Journal of immunology (Baltimore, Md.: 1950) 203, 500-510.http://doi.org/10.4049/jimmunol.1900262.

8. Cobo, T., M. Kacerovsky, and B. Jacobsson. 2014. Amniotic fluid infection, inflammation, and colonization in preterm labor with intact membranes. American Journal of Obstetrics and Gynecology 211, 708.http://doi.org/10.1016/j.ajog.2014.06.060.

9. Yin, N., H. Zhang, X. Luo, Y. Ding, X. Xiao, X. Liu, N. Shan, X. Zhang, Q. Deng, B. Zhuang, and H. Qi. 2014. IL-27 activates human trophoblasts to express IP10 and IL-6: implications in the immunopathophysiology of preeclampsia. Mediators of inflammation 2014,

926875.http://doi.org/10.1155/2014/926875.

10. He, J., Q. Zhang, W. Zhang, F. Chen, T. Zhao, Y. Lin, J. Li, Y. Liu, Y. Liu, and Y. Shao. 2018. The interleukin-27 -964A > G polymorphism enhances sepsisinduced inflammatory responses and confers susceptibility to the development of sepsis. Crit Care 22: 248. http://doi.org/10.1186/s13054-018-2180-0. 
11. Wong, H. R., N. Z. Cvijanovich, M. Hall, G. L. Allen, N. J. Thomas, R. J. Freishtat, N. Anas, K. Meyer, P. A. Checchia, R. Lin, M. T. Bigham, A. Sen, J. Nowak, M. Quasney, J. W. Henricksen, A. Chopra, S. Banschbach, E. Beckman, K. Harmon, P. Lahni, and T. P. Shanley. 2012. Interleukin-27 is a novel candidate diagnostic biomarker for bacterial infection in critically ill children. Crit Care 16, R213.http://doi.org/10.1186/cc11847.

12. Xu, F., Q. Liu, S. Lin, N. Shen, Y. Yin, and J. Cao. 2013. IL-27 is elevated in acute lung injury and mediates inflammation. Journal of clinical immunology 33 : 1257-1268. http://doi.org/10.1007/s10875-013-9923-0.

13. Fan, J., Y. C. Zhang, D. F. Zheng, M. Zhang, H. Liu, M. He, and Z. J. Wu. 2020. IL-27 is elevated in sepsis with acute hepatic injury and promotes hepatic damage and inflammation in the CLP model. Cytokine 127: 154936. http://doi.org/10.1016/j.cyto.2019.154936.

14. Yin, N., H. Wang, H. Zhang, H. Ge, B. Tan, Y. Yuan, X. Luo, D. M. Olson, P. N. Baker, and H. Qi. 2017. IL-27 induces a pro-inflammatory response in human fetal membranes mediating preterm birth. International immunopharmacology 50: 361-369. http://doi.org/10.1007/s12253-017-0295-2.

15. Kim, C. J., R. Romero, P. Chaemsaithong, N. Chaiyasit, B. H. Yoon, and Y. M. Kim. 2015. Acute chorioamnionitis and funisitis: definition, pathologic features, and clinical significance. American Journal of Obstetrics and Gynecology 213: S29-S52. http://doi.org/10.1016/j.ajog.2015.08.040.

16. Karjalainen, M. K., M. Ojaniemi, A. M. Haapalainen, M. Mahlman, A. Salminen, J. M. Huusko, T. A. Määttä, T. Kaukola, J. Anttonen, J. Ulvila, R. Haataja, K. Teramo, S. F. Kingsmore, A. Palotie, L. J. Muglia, M. Rämet, and M. Hallman. 2015. CXCR3 Polymorphism and Expression Associate with Spontaneous Preterm Birth. Journal of immunology (Baltimore, Md.: 1950) 195, 2187-98.http://doi.org/10.4049/jimmunol.1501174.

17. Mizoguchi, M., Y. Ishida, M. Nosaka, A. Kimura, Y. Kuninaka, T. Yahata, S. Nanjo, S. Toujima, S. Minami, K. Ino, N. Mukaida, and T. Kondo. 2018. Prevention of lipopolysaccharide-induced preterm labor by the lack of CX3CL1-CX3CR1 interaction in mice. PloS one 13: e0207085.

.http://doi.org/10.1371/journal.pone.0207085.

18. Redline, R. W. 2012. Inflammatory response in acute chorioamnionitis. Semin. Fetal Neonatal Med. 17: 20-25. http://doi.org/10.1016/j.siny.2011.08.003.

19. Tong, M., and V. M. Abrahams. 2020. Neutrophils in preterm birth: Friend or foe? Placenta 102, 17-20.http://doi.org/10.1016/j.placenta.2019.12.010.

20. Rinaldi, S. F., R. D. Catalano, J. Wade, A. G. Rossi, and J. E. Norman. 2014. Decidual neutrophil infiltration is not required for preterm birth in a mouse model of infection-induced preterm labor. Journal of immunology (Baltimore, Md.: 1950) 192, 2315-25.http://doi.org/10.4049/jimmunol.1302891.

21. Mateer, S. W., A. Mathe, J. Bruce, G. Liu, S. Maltby, M. Fricker, B. J. Goggins, H. L. Tay, E. Marks, G. Burns, R. Y. Kim, K. Minahan, M. M. Walker, R. C. Callister, P. S. Foster, J. C. Horvat, P. M. Hansbro, and S. Keely. 2018. IL-6 Drives Neutrophil-Mediated Pulmonary Inflammation Associated with Bacteremia in Murine Models of Colitis. The American journal of pathology 188: 1625-1639. http://doi.org/10.1016/j.ajpath.2018.03.016.

22. Uyama, N., H. Tsutsui, S. Wu, K. Yasuda, E. Hatano, X. Y. Qin, S. Kojima, and J. Fujimoto. 2019. Anti-interleukin-6 receptor antibody treatment ameliorates postoperative adhesion formation. Scientific reports 9: 17558. .http://doi.org/10.1038/s41598-019-54175-1.

23. Sun, K., S. L. Salmon, S. A. Lotz, and D. W. Metzger. 2007. Interleukin-12 promotes gamma interferon-dependent neutrophil recruitment in the lung and improves protection against respiratory Streptococcus pneumoniae infection. Infection and immunity 75: 1196-1202. http://doi.org/10.1128/iai.0140306.

24. Peshkova, I. O., T. Aghayev, A. R. Fatkhullina, P. Makhov, E. K. Titerina, S. Eguchi, Y. F. Tan, A. V. Kossenkov, M. V. Khoreva, L. V. Gankovskaya, S. M. Sykes, and E. K. Koltsova. 2019. IL-27 receptor-regulated stress myelopoiesis drives abdominal aortic aneurysm development. Nat Commun 10: 5046. .http://doi.org/10.1038/s41467-019-13017-4.

25. Cossío, I., D. Lucas, and A. Hidalgo. 2019. Neutrophils as regulators of the hematopoietic niche. Blood 133: 2140-2148. http://doi.org/10.1182/blood2018-10-844571.

26. Rossi, D., and A. Zlotnik. 2000. The biology of chemokines and their receptors. Annual review of immunology 18, 217 42.http://doi.org/10.1146/annurev.immunol.18.1.217.

27. Boldenow, E., C. Gendrin, L. Ngo, C. Bierle, J. Vornhagen, M. Coleman, S. Merillat, B. Armistead, C. Whidbey, V. Alishetti, V. Santana-Ufret, J. Ogle, M. Gough, S. Srinouanprachanh, J. W. MacDonald, T. K. Bammler, A. Bansal, H. D. Liggitt, L. Rajagopal, and K. M. Adams Waldorf 2016. Group B Streptococcus circumvents neutrophils and neutrophil extracellular traps during amniotic cavity invasion and preterm labor. Sci Immunol 1.http://doi.org/10.1126/sciimmunol.aah4576.

28. Birkholz, J., A. Doganci, C. Darstein, S. Gehring, F. Zepp, and C. U. Meyer. 2014. IL-27 improves migrational and antiviral potential of CB dendritic cells. Human immunology 75, 584 - 91.http://doi.org/10.1016/j.humimm.2014.02.004.

29. Griffith, J. W., C. L. Sokol, and A. D. Luster. 2014. Chemokines and chemokine receptors: positioning cells for host defense and immunity. Annual review of immunology 32: 659-702. http://doi.org/10.1146/annurev-immunol-032713-120145.

30. Bollapragada, S., R. Youssef, F. Jordan, I. Greer, J. Norman, and S. Nelson. 2009. Term labor is associated with a core inflammatory response in human fetal membranes, myometrium, and cervix. American Journal of Obstetrics and Gynecology 200: 104.e1. 11.http://doi.org/10.1016/j.ajog.2008.08.032.

31. Owaki, T., M. Asakawa, N. Morishima, I. Mizoguchi, F. Fukai, K. Takeda, J. Mizuguchi, and T. Yoshimoto. 2008. STAT3 is indispensable to IL-27-mediated cell proliferation but not to IL-27-induced Th1 differentiation and suppression of proinflammatory cytokine production. Journal of immunology (Baltimore, Md.: 1950) 180, 2903-11.http://doi.org/10.4049/jimmunol.180.5.2903.

32. Gan, Y., S. Guo, Y. Zhu, J. Jiang, and Y. Tan. 2019. Exogenous intrapleural injection of interleukin-27 may improves outcome and prognosis in patients with tuberculous pleural effusion. Medical Hypotheses 131: 109319. .http://doi.org/10.1016/j.mehy.2019.109319.

33. Watzlawick, R., E. E. Kenngott, F. D. Liu, J. M. Schwab, and A. Hamann. 2015. Anti-Inflammatory Effects of IL-27 in Zymosan-Induced Peritonitis: Inhibition of Neutrophil Recruitment Partially Explained by Impaired Mobilization from Bone Marrow and Reduced Chemokine Levels. PloS one 10, e0137651.http://doi.org/10.1371/journal.pone.0137651.

34. Quirino, G. F. S. 2016. Interleukin-27 (IL-27) Mediates Susceptibility to Visceral Leishmaniasis by Suppressing the IL-17-Neutrophil Response. Journal of immunology (Baltimore, Md.: 1950) 84, 2289-2298.http://doi.org/10.4049/jimmunol.1501204.

Page 6/9 
35. Tait Wojno, E. D., C. A. Hunter, and J. S. Stumhofer. 2019. The Immunobiology of the Interleukin-12 Family: Room for Discovery. Immunity 50, $851-$ 870.http://doi.org/10.1016/j.immuni.2019.03.011.

\section{Figures}

A

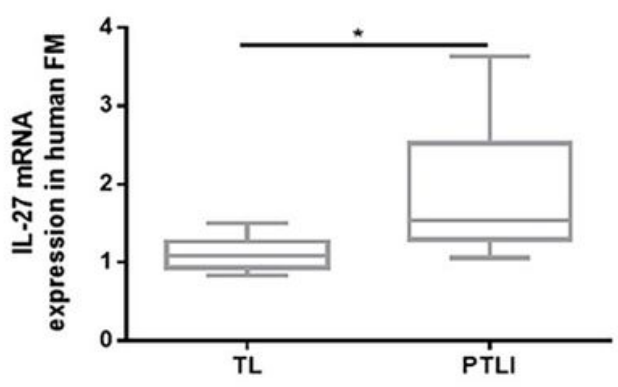

C

\section{IL-27R $\alpha$}

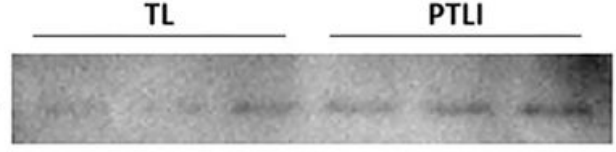

$\beta$-actin
B

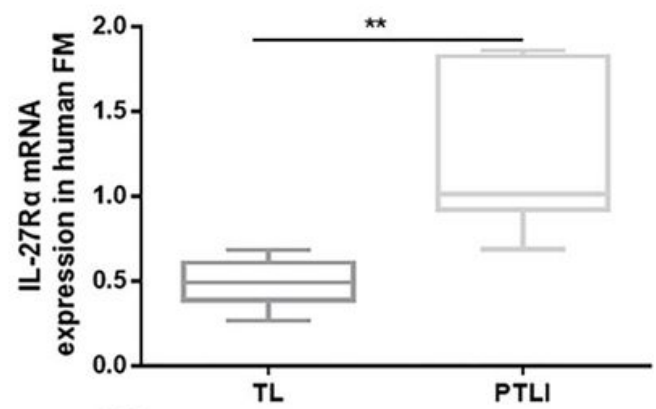

D

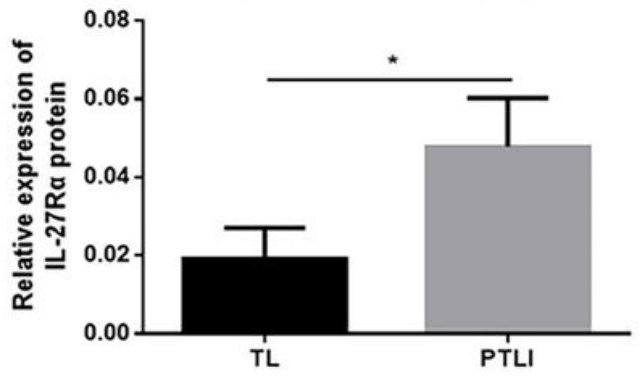

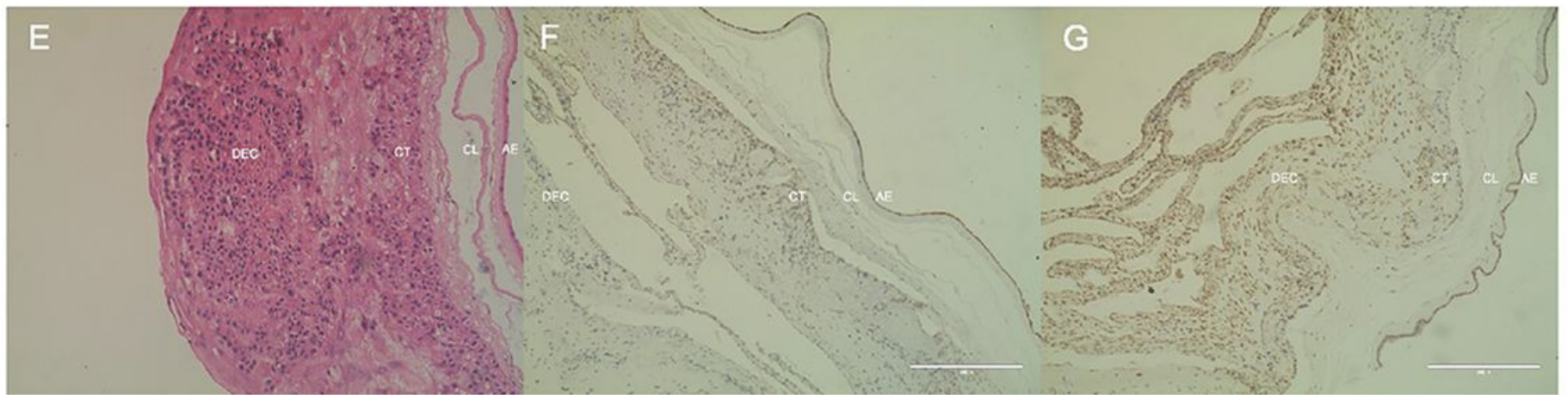

\section{Figure 1}

IL-27 and IL-27R expression in human FMs. (A) Comparison of IL-27 mRNA expression and IL-27Ra mRNA(B) in human fetal membranes of TL group $\mathbb{n}=8 \mathrm{Z}$

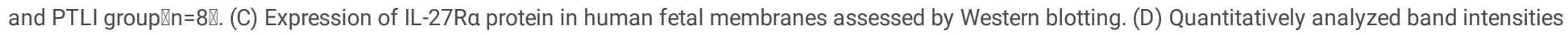
of IL-27Ra, normalized against $\beta$-actin. (E) H\& E staining of fetal membranes. (F) Immunohistochemical staining for IL-27Ra in human FM from TL group and (G) PTLI group. AE, amnion epithelium; CL, connective tissue layer; CT, chorionic trophoblast layer; DEC, decidua. Scale bar (E) $200 \mu \mathrm{m},(\mathrm{F}-\mathrm{G}) 400 \mu \mathrm{m}$. $* \mathrm{p}<$ $0.05, * * p<0.01$, and $* * * p<0.001$ 

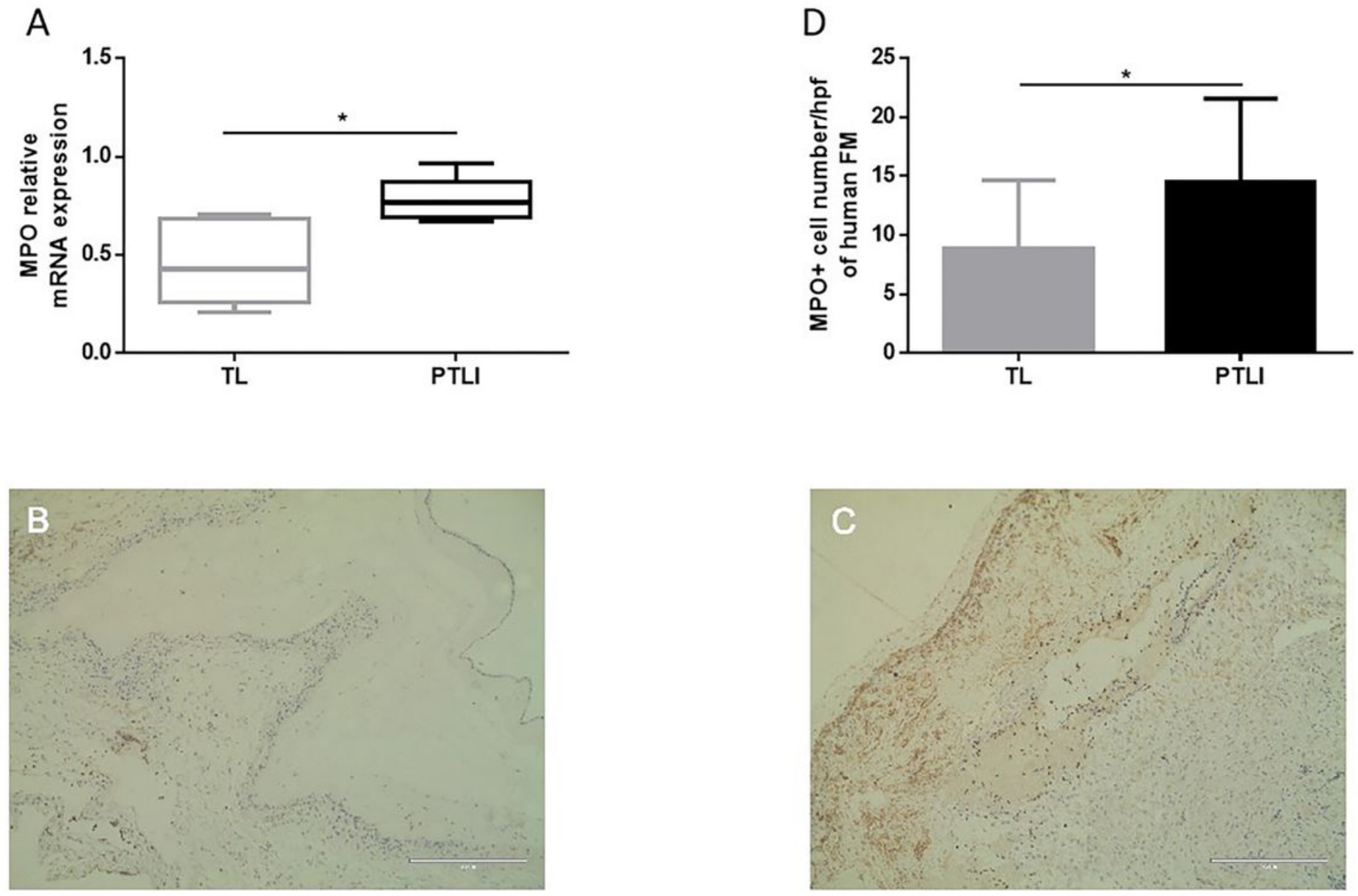

\section{Figure 2}

Neutrophils (MPO+ cells) in human FMs. (A) Comparison of MPO mRNA expression in human FMs of TL group and PTLI group. (B) Immunohistochemical staining for MPO in human FMs of TL group and (C) PTLI group. (D) Comparison of MPO+ cells' number/HPF in human FM of TL group(n=5) and PTLI group $(n=5)$. Scale bar (B-C) $400 \mu m$
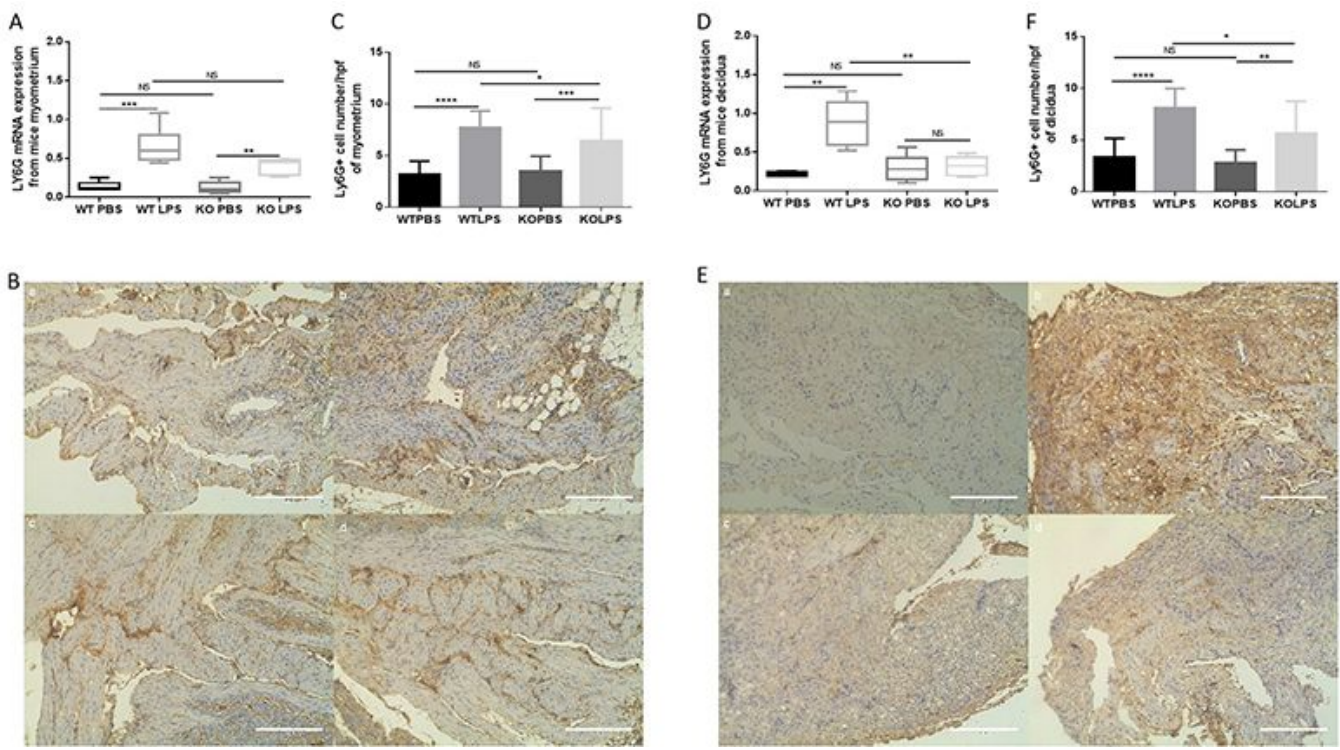

\section{Figure 3}

Leukocytes (Ly6G+ cells) in mice myometrium and decidua. (A) Comparison of Ly6G mRNA expression in mice myometrium and (D) decidua ( $n=8$, for each group). (B) Immunohistochemical staining for Ly6G in mice myometrium and (E) decidua ( $n=5$, for each group) (E). a: WT+PBS, b: WT+LPS, $\mathrm{C}$ : KO+PBS, d: KO+LPS. (C) Comparison of Ly6G+ cells number/HPF in mice myometrium and (F)decidua. WT+PBS: pregnant WT mice at gd 16.5 after PBS treatment. 
WT+LPS: pregnant WT mice at gd 16.5 after LPS treatment. KO+PBS: pregnant IL-27Ra-/- mice at gd 16.5 after PBS treatment. KO+LPS: pregnant IL-27Ra-/mice at gd 16.5 after LPS treatment. Scale bar (B, E) $200 \mu \mathrm{m}$

\section{Supplementary Files}

This is a list of supplementary files associated with this preprint. Click to download.

- SupTable1.doc

- Supgraphicalabstract.tif 